\title{
НОРМЫ ПРАВА: СТРУКТУРА И КЛАССИФИКАЦИИ
}

\section{RULE OF LAW, ITS STRUCTURE AND CLASSIFICATION}

\section{S. Martynova}

Summary. The article analyzes the issues of the structure and classification of legal norms. The author considers this problem by examining the concept, principles, essence of the rule of law. An attempt was made to solve the following tasks: 1) substantiate the relevance of systematization of existing classifications of legal norms; 2) highlight the criteria for the classification of legal norms, based on their regulatory role and value: for the state, society or individual. The work uses such methods as the general dialectical method of scientific knowledge, methods of comparison, analysis and generalization. Based on the opinions of scientists and the provisions of civil, civil procedure law, the article examines the concept of a rule of law, its structure, existing approaches to classification.

Keywords: rule of law, rule of behavior, signs of a rule of law, structure of a rule of law, types of rules of law.

\author{
Мартынова Светлана Владимировна \\ Аспирант, Московский гуманитарный университет \\ beliixvost@mail.ru
}

Аннотация. В статье анализируются вопросы структуры и классификации норм права. Автор рассматривает данную проблему путем исследования понятия, принципов, сущности нормы права. Предпринята попытка решить следующие задачи: 1) обосновать актуальность систематизации существующих классификаций норм права; 2) выделить критерии классификации норм права, основываясь на их регулирующей роли и ценности: для государства, общества или личности. В работе использованы такие методы как общий диалектический метод научного познания, методы сравнения, анализа и обобщения. В статье на основании мнений ученых и положений гражданского, гражданско- процессуального права рассмотрено понятие нормы права, ее структуры, существующие подходы к классификации.

Ключевые слова: норма права, правило поведения, признаки нормы права, структура нормы права, виды норм права.

норм права со стороны полномочных органов государства; способность норм права урегулировать существующие в обществе правоотношения; особую структуру и государственную гарантированность норм права; обеспеченность норм права с помощью принудительной силы государства.

Неоспоримая значимость, ценность норм права заключается в их регулирующей роли, поскольку именно они закрепляют необходимые для общества и государства отношения, придают им стабильность, что позитивно влияет на их дальнейшее развитие. Кроме того, с помощью норм права осуществляется охрана общества и государства от возможных нарушений путем воздействия на нежелательные отношения через определенные ограничения и их полную ликвидацию.

Таким образом, имеются основания считать, что норма права является общеобязательным правилом поведения, которое установлено или санкционировано государством.

Вышеизложенное в полном объеме раскрывает сущность нормы права. Тем не менее, данный вопрос оста- 
ется дискуссионным, поэтому необходимо рассмотреть имеющиеся подходы к определению анализируемого понятия, сформулированные в научной литературе.

Так С.С. Алексеевым под нормой права предлагается понимать правило поведения, исходящее от государства, которое характеризуется общеобязательностью, формальной определенностью, предоставляет всем участникам общественных отношений определенный набор субъективных юридических прав, налагая на них конкретные субъективные юридические обязанности[1].

В.К.Бабаев придерживается позиции, согласно которой под нормой права понимается общеобязательное веление в виде государственно-властного предписания, которым регулируются общественные отношения[2].

Рассматривая структуру нормы права, изучают ее внутреннее строение, а именно, взаиморасположение и взаимосвязь ее основных частей (структурных элементов). Так, конструирование нормы права осуществляется по модели условного предложения: «если... то... иначе...». То есть ее логическая структура представлена элементами нормы. Основой структуры является их взаимосвязь и системность как одни из базовых качеств права.

Структура нормы права представлена гипотезой, диспозицией и санкцией. Гипотеза указывает на: факты, условия, обстоятельства, при наличии которых подлежат исполнению предписания гипотезы; субъектов, к которым адресована норма права. В диспозиции содержится установленное государством правило (модель) поведения участников регулируемых отношений, если имеются обстоятельства, предусмотренные гипотезой. Санкция является логически завершающим элементом (структурным элементом), содержащим указание на конкретные неблагоприятные последствия, которые возникают вследствие нарушения диспозиции.

Взаимодействуя между собой, указанные элементы образуют следующую структуру нормы права: диспозиция определяет модель противоправного поведения; гипотеза определяет условия применения принудительного воздействия; санкция содержит меры применяемого принуждения.

В качестве примера можно привести структуру нормы гражданского процессуального права, содержащейся в ст. 140 ГПК РФ:

1. диспозиция: совершение лицом действий, запрещенных п.п. 2 или 3 ч. 1 ст. 140 ГПК РФ;
2. гипотеза: закон не содержит специального порядка наложения штрафа, в связи с чем используются общие процедуры гражданского судопроизводства (аналогия права);

3. санкция: штраф и возмещение убытков, причиненных действиями нарушителя, в соответствии с ч. 2 ст. 140 ГПК РФ.

Деление нормы права на данные три составляющие называется в науке «логической нормой». Ее элементы взаимосвязаны между собой и проявляются в положениях нормативных правовых актов по условной схеме: «если... то..., а в противном случае... ».

Впервые структурирование норм права на гипотезу, диспозицию и санкцию предложили С.А. Голунский и М.С. Строгович еще в 1940 году[4]. Как известно, их позиция получила широкое распространение в отечественной юриспруденции [6]. Вместе с тем, не все правоведы разделяют мнение о том, что норма права представлена тремя структурными элементами. В частности, многими дореволюционными юристами обосновывалось двучленное строение нормы права, что объяснялось ими наличием норм права, не обеспеченных санкциями.

Исходя из анализа современной юридической литературы, следует сделать вывод, что до настоящего времени так и не сформировано единство мнений о структуре нормы права.

К настоящему времени юридической наукой сформированы различные подходы к вопросу классификации норм права. Наиболее распространенной является классификация исходя из отрасли права. Согласно ей выделяют нормы конституционного, уголовного, трудового, гражданского, семейного и иных отраслей права.

Автор полагает, что важное значение имеет классификация, исходя из разграничения роли норм права в регулировании общественных отношений, согласно которой выделяют: регулятивные, правоохранительные и специализированные нормы. Самостоятельной основой возникновения правоотношений служат регулятивные и правоохранительные нормы права. Правоохранительными нормами предусматриваются меры государственного принудительного воздействия за совершение нарушений. В них всегда содержатся санкции, и они всегда рассчитаны на неправомерное поведение субъекта. Таким образом, взаимодействие регулятивных и правоохранительных норм состоит в том, что первыми регулируются правомерные действия людей, а с помощью вторых государством выражается отрицательная реакция на неправомерное поведение. То есть 
правоохранительные нормы нацелены на охрану регулятивных норм, в них заложено государственное принуждение. С их помощью осуществляется регламентация мер юридической ответственности. Примером тому является, например, ст. 306 ГК РФ, в соответствии С которой: «В случае принятия Российской Федерацией закона, прекращающего право собственности, убытки, причиненные собственнику в результате принятия этого акта, в том числе стоимость имущества, возмещаются государством. Споры о возмещении убытков разрешаются судом».

В свою очередь, в специализированных нормах содержатся предписания, которыми обеспечивается понимание и действие регулятивных и правоохранительных норм. Среди специализированных норм права выделяются: общезакрепительные (конститутивные), дефинитивные, декларативные (целеустановительные), коллизионные и оперативные нормы. Они носят дополнительный характер, поскольку не являются самостоятельной основой для возникновения правоотношений. Так, например, дефинитивными нормами права закрепляются определенные юридические понятия, при их использовании в официальном обороте создаются юридически значимые конструкции, а также конкретные виды правоотношений. Примером могут служить положения ст. 48 ГК РФ, в которой дается понятие юридического лица.

«Среди специализированных норм права особое место занимают системоопределяющие (учредительные, нормы-цели, нормы-принципы, дефинитивные) правовые нормы, которые собственно и формируют модель правового регулирования, определяют нравственные, идеологические основания действия права» [3, с. 14]. Системоопределяющие специализированные нормы помогают формировать систему права, объединяют множество норм в единое целостное образование, связывают её элементы, определяют их место в системе.

Исходя из сферы (объема) регулирующего действия, нормы права можно подразделить на: общие, специальные и исключительные.

Общими нормами регулируются общественные отношения определенного рода, а специальными - соответствующие виды отношений. Иными словами, общие нормы права отвечают за регулирование более широкого круга общественных отношений путем применения достаточно высокой меры их обобщения.

В специальных нормах содержатся более детализированные предписания (если сравнивать их с общими нормами права), поскольку они полнее учитывают особенности общественных отношений. Вместе с тем, их особенности взаимосвязаны с конкретной категорией субъектов. Это наглядно прослеживается, например, в трудовом праве, где распространяющиеся на всех работников общие нормы сочетаются со специальными, дифференцированными сначала отдельно в отношении рабочих и служащих, а потом - по особым категориям служащих.

В науке также принято выделять так называемые типичные и нетипичные нормы права. «Нетипичные нормы права не являются правилами поведения субъектов права в конкретной ситуации, а содержат определённые положения, обеспечивающие действие типичных норм права» [5, с. 24]. В качестве примера нетипичных норм можно назвать так называемые «каучуковые» нормы, т.е. нормы неопределённого, эластичного содержания, включающие в себя формулировки, в которые может быть вложен различный смысл - «добрая совесть», «добрые нравы», «разумный срок» и т.п. Нетипичные нормы весьма разнообразны, можно выделить такие нетипичные нормы как общезакрепительные, дефинитивные, декларативные, коллизионные, оперативные нормы.

По результатам анализа предлагается выделять такой критерий классификации норм права как субъект оценивания. В этом случае нормы права будут группироваться, исходя из того, чьи ценности они закрепляют и кем они оцениваются: ценности общества, государства или личности. Причем эта проблема является не решенной в настоящее время в юридической науке. Так, отмечается такое правовое явление, когда одна и та же норма оценивается по-разному. «Если законодатель осуществляет общую и обязательную к применению конкретизацию оценочной нормы права, то правоприменитель осуществляет свободную оценку, осмысление конкретной ситуации и соотношение ее с относительно-определенной нормой сквозь призму его правосознания» [7, с. 67]. Нельзя забывать и то, что конкретизация норм осуществляется как правоприменителем, так и обычным гражданином, субъектом права. Так, в зависимости от субъекта можно выделить частную и судебную конкретизацию норм гражданского права, что имеет большое значение для юридической практики.

Таким образом, под нормой права следует понимать общеобязательное правило поведения, которое установлено или санкционировано государством. Кроме рассмотренных классификаций, имеют место и другие, что дает основания утверждать о высоком уровне дискуссионности данного вопроса в теории права. По результатам анализа предложено использовать такой критерий классификации норм права как субъект оценивания. 


\section{ЛИТЕРАТУРА}

1. Алексеев С.С. Государство и право. Начальный курс. М., 1994. 192 с.

2. Бабаев В.К. Общая теория права: Курс лекций. Н. Новгород, 1993. 544 с.

3. Баранов А.В. Системоопределяющие специализированные нормы современного российского права // Вестник Омского университета. Серия «Право». 2017. № . 4 (53). С. 13-19.

4. Голунский С.А., Строгович М.С. Теория государства и права. М., 1940.304 с.

5. Рыбаков В.А. Нетипичные нормы права // Вестник Омского университета. Серия «Право». 2013. № 3 (36). С. 24-29.

6. Томашевский Н.П. 0 структуре правовой нормы и классификации ее элементов // Вопросы общей теории советского права. М.,1960.С. 180-185.

7. Фатхи В.И., Хакимов И.А. Роль правосознания в конкретизации норм гражданского права // Философия права. 2017. № 3. С. 62-67.

( ) Мартынова Светлана Владимировна ( beliixvost@mail.ru ).

Журнал «Современная наука: актуальные проблемы теории и практики»

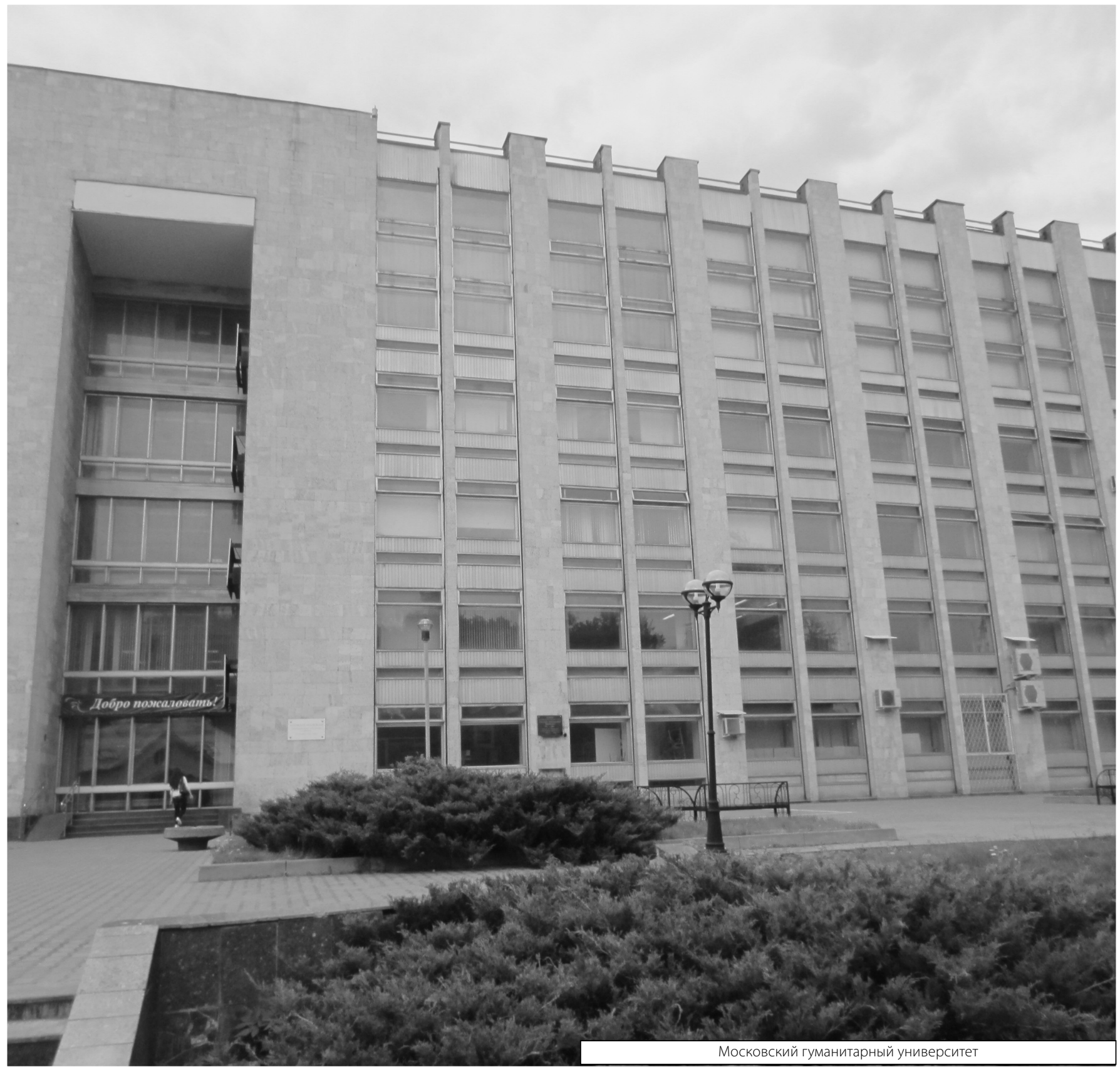

